\title{
Compreensão (con)textual em mídias sociais digitais
}

\author{
(Con)text comprehension in digital social media
}

\section{Alana Kercia Barros Demétrio \\ Luiz Eleildo Pereira Alves \\ Maria Helenice Araújo Costa}

Universidade Estadual do Ceará - UECE - Fortaleza - Ceará - Brasil

Resumo: Neste artigo, abordamos a questão da leitura sob o ponto de vista da complexidade. Considerando com Beaugrande (1997) que o texto é um evento comunicativo cuja configuração envolve elementos de diferentes naturezas, incluindo os participantes da interação, entendemos que as abordagens tradicionais da leitura, mesmo as que se voltam para a interação, não amparam satisfatoriamente a compreensão do fenômeno. Com o intuito analisar de que modo aspectos que caracterizam a leitura como atividade complexa se manifestam na compreensão (con)textual em mídias sociais digitais, apoiamo-nos nos trabalhos de Pellanda (2005) e de Franco (2011) e tomamos por base a teoria autopoiética de Maturana e Varela (1995), bem como as noções de emergência e incorporação de Hanks (2008). Por meio da análise de dois exemplos de interação veiculados em ambiente virtual, observamos que a leitura desencadeia a autopoiese dos leitores enquanto sistemas vivos.

Palavras-chave: Linguagem. Complexidade. Autopoiese. Leitura. Emergência. Incorporação.

\begin{abstract}
In this article, we address the reading issue from the point of view of complexity. Understanding, according to Beaugrande (1997), that the text is a communicative event whose configuration involves elements of different nature, including the participants of interaction, we think that traditional approaches to reading, even those which are focused on interaction, do not satisfactorily bolster comprehension of this phenomenon. In order to analyze how aspects that characterize reading as a complex activity show at (con)text comprehension in digital social media, we leaned on the articles by Pellanda (2005) and by Franco (2011) and we were supported by the autopoietic theory by Maturana and Varela (1995), as well as by the concepts of emergency and incorporation by Hanks (2008). Through the analysis of two examples of interaction conveyed in virtual environment, we observed that reading triggers readers' autopoiesis as living systems.
\end{abstract}

Keywords: Language. Complexity. Autopoiesis. Reading. Emergency. Incorporation. 


\section{Introdução}

As abordagens teóricas sobre a leitura há muito, desde meados da década de 60, deixaram de classificá-la como mero ato de decodificação. Em oposição a essa visão centrada no código, surgiram as concepções focadas nos processos puramente cognitivos, as quais, algumas décadas mais tarde, também passaram a ser contestadas (rejeitadas) quando a noção de competência linguística chomskiana foi posta em questão pela perspectiva que situa a linguagem como um fenômeno social. As novas abordagens que surgiram a partir desse período têm procurado desde então dar conta da complexidade dos aspectos envolvidos nesse fenômeno.

Embora levem em consideração os elementos ligados à interação, algumas dessas novas abordagens, segundo nosso entendimento, falham ainda no reconhecimento da dimensão dessa complexidade, como as propostas conceituais que sugerem sequências de estratégias supostamente necessárias ao exercício efetivo da competência leitora ou que definem pretensos pré-requisitos para a concretização de uma leitura crítica, pois, ao vincular a interação a fatores predeterminados, essas propostas negligenciam a contingencialidade constitutiva da atividade discursiva.

Por assumirmos a concepção de texto proposta por Beaugrande (1997), para quem, em qualquer que seja a modalidade, os participantes figuram entre os múltiplos elementos envolvidos no sistema de conexões que configuram esse evento comunicativo, consideramos que a tentativa de se descrever 0 processo de leitura como uma sequência de ações prédefinidas ou um conjunto de habilidades e aptidões genericamente requeridas soa sempre incompleta e inadequada.

Por tomar a leitura como um fenômeno sujeito a uma gama de indeterminações, a abordagem sugerida por Franco (2011), de leitura como um sistema de ação

\footnotetext{
1 Em "A World of Others' Words: Cross-Cultural Perspectives on Intertextuality", Bauman (2004) discute os conceitos de entextualização, descontextualização e recontextualização, argumentando que o processo de entextualização, isto é, a organização de um intervalo discursivo em um texto, potencializa a descontextualização do discurso exatamente por delimitá-lo.
}

complexa, parece-nos mais coerente com essa noção de texto que adotamos. Para o linguista, não se pode prever todas as interações possíveis no processo de leitura, tanto em razão de existirem múltiplos agentes, como leitor, autor, texto, contexto social, contexto histórico, contexto linguístico etc., quanto em virtude de ser o leitor, ele mesmo, um sistema complexo, abastecido de frustrações, expectativas, crenças, conhecimento de mundo etc., alteráveis durante o ato de leitura. Além disso, conforme ele explica, na interação com o leitor, cada um dos outros elementos, os demais agentes, também se convertem em sistemas complexos.

Compreendemos que esse mecanismo de processamento semântico complexificado apresentado nessa abordagem de leitura é bastante condizente com o modo como interagimos com os textos que permeiam massivamente nossas práticas diárias. Chamando atenção exatamente para o bombardeio de textos característico de nosso cotidiano, Marcuschi (2005) discute como somos capazes de produzir sentido e construir coerência em meio à selva textual labiríntica constituída por aquilo que temos como escrita desde que acordamos até o final do dia. Por nos alinharmos com o posicionamento do autor, para quem a "dispersividade discursiva", esse modo desterritorializado e tentacular com que os textos se integram às nossas práticas diárias, corresponde à própria natureza do objeto textual, consideramos que o desenvolvimento da nossa competência leitora nos permite não apenas selecionar, mas associar, diferenciar e reconstruir as informações que se emaranham nessa paisagem vertiginosa representada pelos inúmeros textos circulantes em nosso entorno.

A nosso ver, essas operações se tornam possíveis a partir do movimento contínuo de descontextualização e recontextualização dos sentidos que, de acordo com Bentes e Rezende (2008), todo texto pressupõe. Apoiados nesse postulado de Bauman (2004) ${ }^{1}$, os autores sustentam

Assevera que a descontextualização, por seu turno, implica necessariamente a recontextualização, pois um intervalo é destituído de um contexto discursivo apenas para ser reconstituído em outro. 
que os textos apresentam o potencial de circulação e consumo em contextos distintos do contexto de produção. Explicam que é esse movimento, de descontextualizar para necessariamente recontextualizar, que nos permite objetivar um determinado trecho do discurso como uma unidade textual discreta e então construir coerência para essa unidade.

Ocorre que o desenvolvimento das tecnologias digitais da comunicação nos fez olhar de modo mais atento para esse movimento de descontextualização/recontextualização.

surgimento e a consolidação daquilo a que Lévy (1999) se refere como Cibercultura parecem conferir ao movimento ainda mais instabilidade, uma vez que apontam para uma espécie de compartilhamento generalizado do contexto. Segundo o autor, a imersão dos interactantes em um dilúvio informacional, implicada no ciberespaço, não permite "fechamento semântico" ou "totalização" dos sentidos, pois qualquer texto é um fragmento de um hipertexto móvel, em evolução constante; qualquer mensagem está mergulhada no "banho comunicacional fervilhante de vida" (p. 118) que resulta da "interconexão e [d]o dinamismo em tempo real das memórias on-line" ( $p$. 118).

Considerando nosso propósito de discutir de que modo aspectos que caracterizam a leitura como atividade complexa se manifestam na compreensão (con)textual em mídias sociais digitais, organizamos este artigo em duas seções. Na primeira, realizamos uma breve discussão teórica em torno da abordagem complexa da leitura diante do abundante, disperso e ubíquo fluxo discursivo que caracteriza nosso cotidiano, especialmente no ambiente virtual; em seguida, abrimos um tópico, na seção, para tecer considerações sobre a noção de contexto, irremediavelmente posta em relevo no debate sobre o modo como a compreensão textual se constrói. Na segunda, analisamos exemplos de interação no ambiente das mídias digitais à luz das reflexões sobre a complexidade no uso da linguagem e, especificamente, no processo de leitura.

\section{Complexidade, leitura e ambiente virtual}

Conforme Pellanda (2007), os estudos ligados à cognição encontram hoje, nos novos pressupostos da complexidade, um instrumental de abordagem mais profícuo diante das emaranhadas teias de relações que caracterizam os diversos aspectos da realidade humana. O paradigma da complexidade constitui-se, segundo a autora, em torno de uma questão crucial, a de que a cognição é um processo vivo e inseparável do processo ontológico.

Nesse sentido, Pellanda considera a atividade de leitura, enquanto processo cognitivo, elemento de autoconstrução e de construção social simultaneamente. Pondera, por outro lado, que o extremo racionalismo e a consequente fragmentação das dimensões do humano, os quais fomentaram uma visão de conhecimento como expressão da racionalidade e do desvelamento de uma suposta realidade apriorística, amputaram da leitura essa sua missão duplamente constitutiva.

Rompendo com as fragmentações, simplificações e generalizações de uma concepção de leitura regida por uma lógica formal, Pellanda (2005, p. 53) trata o fenômeno

como um processo de "fazer emergir" através da atividade interna de recriação do texto com autonomia (autoria) e, ao mesmo tempo, resultante da interação de forma inseparável do próprio processo de viver e tornar-se. Nesse sentido, a leitura seria um dispositivo da cognição e do sujeito que nos perturbaria, mobilizando-nos para que possamos nos inventar de forma autônoma.

Para a autora, essa "releitura da leitura" é proporcionada por um paradigma que sustenta relações em vez de propriedades e devires em vez de realidades acabadas; sob esse paradigma, o texto seria um evento dotado de um equilíbrio dinâmico e potencialmente perturbador de nossas subjetividades. A reflexão de Pellanda sobre a questão está ancorada na Biologia da Cognição, de Humberto Maturana e Francisco Varela. Esses biólogos chilenos cunharam o termo autopoiesis (1995) para referir-se ao modo de organização de um ser vivo, que para eles seria um sistema fechado, dependente das interações com outros sistemas (os outros, o meio, os objetos etc.), e 
em contínua produção de si mesmo, reagindo às perturbações externas. De acordo com essa concepção autopoética da vida, não há segmentação entre mecanismos cognitivos e ontológicos, uma vez que os seres vivos se (re)constituem a partir das atividades cognitivas desencadeadas por essas perturbações. Os modos de reagir constituem formas de "acoplamento estrutural", ou seja, ajustes operacionais com vistas à manutenção da organização. Enquanto sistemas que se autoproduzem, agimos desenvolvendo de forma contínua "coordenações consensuais de ações”. Como seres "linguajantes" (MATURANA, 2001), tornamos recursivo esse processo de coordenação, isto é, praticamos, "coordenações consensuais de coordenações consensuais de ações", agimos pela linguagem sobre a linguagem e, assim, produzimos sentido.

Pensando o texto nessa perspectiva, "como um instrumento de perturbação que dispara em nós mecanismos cognitivos e ontológicos", Pellanda (2005, p. 59) apresenta a leitura como uma maneira de o leitor, engajado na interação com esse instrumento, reorganizar-se, (re)subjetivando-se e estabelecendo com a realidade novas relações. O dinamismo desse movimento, que Pellanda reconhece como uma "circularidade constante entre virtualização e atualização" (p. 63) em espiral infinita, indica que um texto jamais está pronto, e que o que a leitura nos oferece, portanto, não é a possibilidade de apreender uma realidade representada, mas uma experiência corporificada de (re)significação.

Esse modo de compreender o processo de leitura encontra amparo na teoria da complexidade justamente por assentar-se na ideia de que tanto leitor como texto são sistemas adaptativos complexos. Segundo Franco (2011), a auto-organização resultante da troca de energia entre as partes e com o meio externo é que complexifica a totalidade do movimento. "Como os sistemas não são lineares, [nem os sujeitos nem a linguagem,] causa e efeito não assumem uma relação proporcional e também não é possível prever precisamente quando um comportamento aleatório vai ocorrer" (p. 39).
O autor salienta que, estando suscetível a múltiplas e imprevisíveis possibilidades de interações e indeterminações, o fluxo de informações no processo de leitura conduz-se de modo multidimensional. É impossível mapear sua trajetória, uma vez que as relações entre os diversos e contingentes elementos se estabelecem adaptativamente num equilíbrio apenas precário. Para Franco, essa condição tornaria a leitura um sistema de ação complexo por ser ele aberto, porquanto "novas interações emergem com a troca de informações dentro do sistema e com o ambiente externo" (p. 41).

Caracterizando dessa forma um sistema complexo, o autor nos leva a refletir sobre o aparente paradoxo de admitirmos a premissa da concepção autopoiética, a de que um sistema adaptativo complexo, que tende à auto-organização quando desestabilizado, possa ser entendido como um sistema fechado. O comentário de Pellanda (2005) sobre a questão concilia, a nosso ver, um e outro modo de pensar a presença da complexidade em um sistema no que diz respeito à interação com aquilo que se encontra fora dele. Um sistema vivo, diz a autora, apresenta-se simultaneamente "como sistema fechado à informação, mas aberto à energia, na medida em que as interações abrem o sistema para novos patamares de organização ascendentes" (p. 61).

Compreendemos assim que o que ocorre no processo de leitura não é de fato entrada (recepção), aquisição, absorção de informação, mas perturbação (perda de energia), desordem e rearranjo com vistas à reversão produtiva do desequilíbrio. A autoorganização adaptativa é o que impede, portanto, que o movimento desencadeado no processo seja linear ou previsível.

A ausência de linearidade, de uma ordenação canônica no processo de leitura é bastante enfatizada por Marcuschi (2005) para questionar a existência de uma distinção nítida e definida entre texto e hipertexto. Segundo o autor, ao assumirmos a noção de texto proposta por Beaugrande (1997), para quem todo texto é um evento comunicativo e interativo que emerge de um sistema de conexões entre elementos linguísticos, cognitivos e sociais, percebemos que o hipertexto só 
parece dicotômico à ideia tradicional de estrutura textual estável. A não linearidade, a imprevisibilidade, a dinamicidade são, pois, características atribuíveis à própria atividade de leitura enquanto processo de atualização da virtualidade textual.

Esclarecida de antemão essa questão, as peculiaridades da leitura em ambiente virtual que interessam à nossa discussão dizem respeito a elementos que de fato interferem no processo, como a profusão informacional combinada à simultaneidade interacional e à copresença virtual de uma quantidade incalculável de participantes; ressaltamos, portanto, que não sustentamos uma espécie de natureza própria, de caracterização intrínseca, dos textos digitais.

A presença desses elementos no ambiente virtual, conforme entendemos, torna ainda mais evidente o funcionamento caótico da leitura, uma vez que as alterações inesperadas e as consequências produzidas em cascata dentro do sistema alcançam proporções incomensuráveis neste tipo de interação, a que ocorre entre os bilhões de leitores que ocupam o mesmo espaço (rede mundial de interconexões) e os textos que nele circulam.

A metáfora apresentada por Lévy (1999) para conceptualizar a cibercultura corresponde a um dilúvio infinito de informações em um oceano sem fundo sólido diante do qual não há apenas uma Arca, mas várias embarcações navegando à deriva, sem Noés absolutos, sem seleções universais, dançando entre si e trocando sinais. A nosso ver, essa metáfora auxilia a compreensão do que afirmamos no parágrafo anterior na medida em que alude ao surgimento de um novo universal, uma universalidade que, nas palavras de Lévy (p. 15), "se constrói e se estende por meio da interconexão das mensagens entre si, da sua vinculação permanente com as comunidades virtuais em criação, que Ihe dão sentidos variados em uma renovação permanente".

Dessa forma, o que emerge em meio ao dilúvio são "pequenas totalidades", de modo que não se afogam as espécies que são eventualmente negligenciadas em uma seleção; elas permanecem na corrente. Para o autor, essas "micrototalidades" se opõem à imposição de uma "conjunção estabilizada do sentido de uma pluralidade" (LÉVY, 1999, p. 121); elas apontam para o fato de que qualquer tentativa de "fechamento semântico" se dá "no horizonte de um processo complexo [e resulta] do desequilíbrio dinâmico da vida" (p. 121), ou, conforme entendemos, de um equilíbrio que é apenas precário.

Nesse sentido, reafirmamos a leitura como um processo simultaneamente cognitivo e ontológico, o qual gera em nós ideias, dúvidas, inferências, equívocos, num movimento cuja intensidade depende em grande parte do nosso grau de engajamento, ao passo que nos torna outros como consequência de nosso empenho em reagir aos abalos para restabelecer nosso equilíbrio. Reiteramos, da mesma forma, dois aspectos vinculados a essa concepção, a incompletude do texto e a imprevisibilidade do fluxo interacional que com ele estabelecemos. Um e outro aspecto exigem que nosso olhar se volte agora para a noção de contexto, elemento que condiciona tanto a incompletude quanto a imprevisibilidade.

A exigência dessa recorrência ao contexto justifica-se, a nosso ver, pelas relações de mútua constitutividade que, de acordo com Hanks (2008), essa instância estabelece com a linguagem. Para o autor, essas relações se organizam tanto pela incorporação do discurso em uma dimensão mais ampla, que engloba determinações históricas e socioculturais, quanto pela sua emergência em uma dimensão mais imediata, que abrange a situação, localizada e concreta, de produção e recepção.

Apoiando-se nessa concepção de contexto construída pelo autor, Bentes e Rezende (2008) discutem e procuram demonstrar a ocorrência dos diversos níveis de interpenetração entre o texto e essa instância, favorecendo em larga medida a compreensão da proposta teórica de Hanks. Com base nas contribuições desses autores e nos postulados do próprio Hanks, tecemos no próximo tópico algumas considerações a respeito dessa proposta. 


\subsection{Considerações sobre a noção de contexto}

Apontando o contexto como uma instância da qual depende fundamentalmente a produção de sentido que ocorre mediante o uso da linguagem, Hanks (2008) discute como os estudos que procuraram abordar o fenômeno ou detêm-se a uma perspectiva microanalítica ou concentram-se apenas em um nível macro de análise.

No primeiro grupo, o autor inclui a teoria dos atos de fala, a teoria griceana das máximas conversacionais, a teoria da relevância, a etnometodologia e a análise da conversação. Embora reconheça as grandes contribuições que essas abordagens ofereceram à nossa compreensão da linguagem como interação, Hanks argumenta que elas tratam o contexto como uma estrutura radial em torno do enunciado.

Segundo este ponto de vista, o contexto é um concomitante local da conversação e da interação, efêmero e centrado sobre o processo emergente de fala. Se se coloca ênfase principal sobre o uso efetivo da língua como atestado em situações reais ou sobre exemplos construídos, o quadro de referência e de explicação resultantes são as atividades individuais de fala e as interações verbais nas quais elas ocorrem (HANKS, 2008, p. 171).

Em razão dessa redução das estruturas sociais aos comportamentos individuais, o autor se refere a essas abordagens como individualistas, contrapondoas àquelas que se enquadram no outro grupo, das abordagens em larga escala, em que ele inclui alguns estudos da Análise Crítica do Discurso. Hanks explica que, sob esse outro ponto de vista, em vez de local e efêmero, o contexto é global e duradouro; o escopo social e histórico tem maior peso que o ato localizado. A estrutura radial das abordagens individualistas cede lugar a sistemas de referência explicativos com base em condições sociais e históricas, anteriores à produção do discurso; do mesmo modo, o foco sobre as intenções dos falantes é substituído pela atenção às determinações de forças sociais maiores.

Sustentando a complementaridade dos dois tipos de abordagem, o autor considera estéreis alegações de que um ou outro nível priorizado por esses estudos é mais fundamental para o contexto:

Os cenários locais da enunciação e da interação face-a-face são centrais para o primeiro grupo e ausentes, ou pelo menos marginais, no segundo. Inversamente, os fatos coletivos, centrais para as definições sociais de contexto, são marginais ou simplesmente ignorados nas abordagens individualistas. Esta polarização dá origem a exageros e deixa escapar muitas oportunidades de pesquisa produtiva. Ela torna obscuro como articular diferentes níveis de contexto analiticamente, ou até mesmo se tal articulação é um objetivo adequado. Dado que o discurso responde ao contexto em graus variados, e que nenhum cenário social efetivo pode ser caracterizado apenas sob micro ou macroperspectiva, as duas estão inevitavelmente contrapostas uma à outra (HANKS, 2008, p. 173).

Nesse sentido, a proposta elaborada pelo autor procura dar conta de duas dimensões abrangentes do contexto: a emergência, que designa os aspectos discursivos implicados no curso dos processos de produção e recepção, como a interação, a copresença e a temporalidade; e a incorporação, que diz respeito aos aspectos ligados ao enquadramento discursivo, como a inscrição do discurso em quadros socioculturais mais amplos.

Não se trata simplesmente de aglutinar as abordagens focadas nas práticas enunciativas e as abordagens em larga escala. A originalidade da proposta de Hanks está no fato de que a emergência e a incorporação funcionam articulada e simultaneamente. Hanks teoriza sobre a existência, na primeira dimensão (a emergência), de três formações contextuais: situação, que corresponde ao campo de co-ocupação do espaço/tempo, reciprocidade perceptiva e monitoramento/cooperação mútuo(a) potenciais; cenário, que designa um mero campo de copresença potencial, isto é, uma situação, convertido em um sistema de relevância; e campo semiótico/simbólico/demonstrativo, que compreende um cenário cujas características são transformadas por signos, pelas relações entre eles, pela presença dos objetos significados e por funções de cooperação, como a referência e a diretividade colaborativa. Conforme esclarecem Bentes e Rezende (2008, p. 40-41, grifos nossos), 
[...] a situação, o cenário e o campo semiótico são emergentes no sentido de que se desenvolvem no tempo. A existência dessas diferentes formações contextuais não implica nem a existência de uma sequência temporal entre elas, nem tampouco um conjunto de relações de inclusão. [...] as três formações (ou níveis) contextuais distintas(os) (situação, cenário e campo semiótico/simbólico) encontram-se combinadas(os) entre si de tal forma que, no curso da vida social, não há situação que não esteja ligada a um cenário e não há cenário que possa ser separado das semioses. É essa relação ordenada de envolvimento e de ligação entre os níveis que o autor denomina incorporação (embedding). Para ele, estudar as relações entre a produção de linguagem e o contexto, é estudar essas relações de incorporação social.

Ao descrever essas relações, Hanks (2008) afirma que, quando há incorporação entre formações contextuais, a formação incorporadora herda propriedades da incorporada (como o campo demonstrativo herda as relações de relevância do cenário), mas apresenta outras propriedades, que alteram, por sua vez, as propriedades herdadas (como o sistema semiótico multifuncional do campo demonstrativo reconstitui as relações de relevância do cenário por meio da tematização). O autor acrescenta que, se algum aspecto da formação incorporada é posto em foco, a formação incorporadora é o horizonte relevante (quando há, por exemplo, um problema de relevância no cenário, ele é tratado à luz do campo demonstrativo em curso). Assim, "a incorporação textual nunca é um mero acréscimo ou entorno externo para aspectos do discurso ou da interação" (p. 185).

Hanks ressalta ainda que cenários e campos demonstrativos não existem num vácuo; projetam-se necessariamente em novas incorporações, que são realizadas pelo campo social. O cenário funda-se embrionariamente em mundos além do mundo da copresença, pois "qualquer sistema de relevância ancora seu foco temático dentro de uma história de outros engajamentos com o objeto, de um horizonte de outros objetos relacionados" (p. 189). Por seu turno, ao ser incorporado, o campo demonstrativo torna o campo social "atual, [...] localizado, por sua articulação via relevância, simbolização e evocação indicial” (p. 189), e sujeita seus elementos (atores e objetos) à ocupação de um espaço de posições definidas, fornecidas pelo campo social.

A nosso ver, essa formulação de Hanks sobre o contexto discursivo nos auxilia a pensar o modo como a co-construção dos significados em um texto pressupõe um sistema de relações muito mais complexo do que a correlação direta entre os aspectos globais e locais da produção do discurso. A incorporação, apresentada pelo autor como condição objetiva segundo a qual os diferentes níveis de emergência se configuram e, ainda, conforme a qual esses níveis e a dimensão não intencional da prática comunicativa, o campo social, se co-constituem, parece-nos, assim, um conceito relevante para o estudo.

Ressalvadas as devidas distinções de ordem epistemológica, entendemos ser pertinente, quando tratamos da compreensão leitora, aproximar essa visão antropológica de Hanks (2008) da concepção autopoiética postulada por Maturana e Varela. A nosso ver, as dimensões contextuais emergência e incorporação podem ser consideradas mecanismos pelos quais os leitores, enquanto seres autopoiéticos, reagem às perturbações provocadas pelo texto. A autopoiese - ou as "coordenações consensuais de coordenações consensuais de ação", expressão usada por Maturana (2001, p. 130) para se referir ao funcionamento da linguagem -, poderia ser associado à interação constante entre esses dois "movimentos" propostos por Hanks.

\section{Compreensão (con)textual e complexidade: a leitura no ambiente das mídias sociais}

Segundo nosso entendimento, as reflexões desenvolvidas no tópico anterior acerca da complexidade constitutiva das atividades linguageiras e, mais especificamente, do processo de leitura requerem como corolário uma discussão que, ilustrada por situações de uso da linguagem, torne os conceitos mais claros.

A amostra que selecionamos para analisar compõe-se de dois exemplos de interação no meio digital. A preferência por textos originários desse 
ambiente deveu-se principalmente à possibilidade de acessar o processo via comentários dos leitores. Analisamos a seguir esses dois exemplos de interação que nomeamos de Interação 1 e Interação 2.

\subsection{Interação 1}

A interação 1 desenvolve-se em torno de uma tirinha retirada do site de humor Um sábado qualquer (http://www.umsabadoqualquer.com/?desde-ocomeco), o qual, conforme descrito pelo próprio autor, "explora o lado cômico da existência, a partir do exato momento em que Deus, experimenta "criar o mundo". A proposta, explica o autor do site, não é ofender nenhuma crença religiosa, mas "oferecer, de forma pacífica, a sua versão bem humorada para o princípio do mundo". A tirinha apresentada na interação 1 é a de número 4 de uma série intitulada "Nos bastidores da Arca", composta por 8 tirinhas. A série retrata, a partir da proposta humorística do site, como se deu o famoso episódio bíblico do dilúvio. Segundo é relatado no Livro do Gênesis, Noé construiu uma arca a pedido de Deus com o intuito de abrigar dois animais de cada espécie para, depois de um dilúvio que duraria 40 dias, darem prosseguimento à evolução das criaturas terrestres. Para tanto, segundo é narrado na história bíblica, Deus dá a Noé várias diretrizes para a construção da arca: medidas de largura, extensão, etc.

No episódio a seguir, o autor da tirinha retrata essa passagem bíblica estabelecendo um diálogo com a construção do cavalo de Tróia, instrumento idealizado pelo guerreiro grego Odisseu, que foi utilizado para vencer Tróia em uma guerra ocasionada pelo rapto da princesa Helena, mulher de Menelau, por Páris, príncipe troiano. Conta-se na obra llíada de Homero que, como os gregos não podiam entrar em Tróia, Odisseu propôs aos gregos que construíssem um grande cavalo de madeira onde eles pudessem ficar escondidos. Esse cavalo seria usado para presentear os troianos, como indicação de que desistiam da guerra. Ao aceitar o presente, os troianos introduziram o grande cavalo em seu território.

À noite, quando muitos dos guerreiros inimigos estavam embriagados e dormindo, os gregos saíram de dentro do cavalo e assim venceram seus inimigos, recuperando a mulher de Menelau, Helena.

A partir do exemplo mencionado, discutimos como os leitores reagem à perturbação causada pela leitura do texto. A fim de organizarmos nossa análise, reunimos em blocos os comentários que seguem a tirinha. Cada um desses blocos apresenta um conjunto

Figura 1 - Nos bastidores da Arca, episódio 4
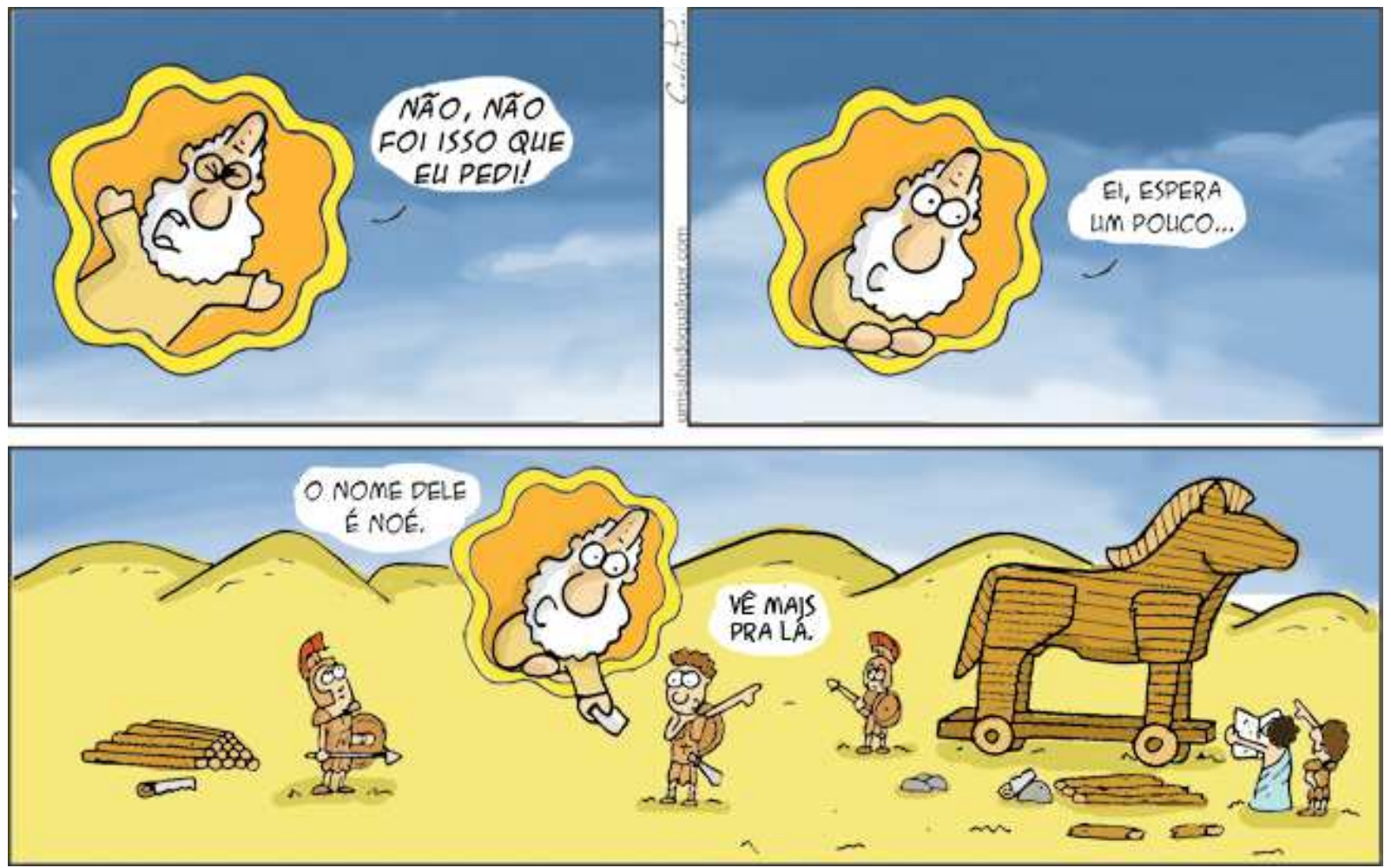

Fonte:https://www.facebook.com/umsabadoqualqueroficial/?target_post=1192069454143597\&ref=story_permalink. Acesso em: 06 de fev. 2016

Signo [ISSN 1982-2014]. Santa Cruz do Sul, v. 41, n. 72, p. 51-64, set./dez. 2016. 
peculiar de indícios de como essa perturbação acontece nos leitores enquanto sistemas vivos.

A leitura da figura 1 provocou nos leitores uma perturbação que desencadeou uma série de tentativas de reorganização sistêmica a partir de diversos mecanismos sociocognitivos. A todo momento os indivíduos tentam fazer novas relações com o texto, realizando autopoiese, conforme veremos nos comentários divididos em blocos. Os comentários são identificados por A1, A2, A3 etc., para o $1^{\circ}$ bloco; B1, B2, B3 etc., para o $2^{\circ}$ bloco; e C1, C2, C3 etc., para o 3ํ bloco.

A1 gente eu não entendi KkkKk sou muito lesada

Curtir · Responder $\cdot 22 \cdot 22$ de outubro de 2015 às 11:55

A2 Deus achou que Noé estava construindo a Arca errado, mas eram os gregos construindo - cavalo pra invadir Troia. Aí ele pediu informação xD

Curtir · Responder · 93 - 22 de outubro de 2015 às 15:03

A3 VIw, eu tbm não tinha entendido kkkkkk Curtir - Responder · 1 - 22 de outubro de 2015 às 12:09

A1 muito bem sacado vlw

Curtir - Responder · 2 - 22 de outubro de 2015 às $12: 19$

A4 Agora sim

Curtir - Responder · 1 - 22 de outubro de 2015 às $12: 26$

A5 Tmb sou lezada! Kkkk Agora sim

Curtir - Responder - 22 de outubro de 2015 às 13:49

A6 É porque faltou um ponto de interrogação quando ele pergunta se é Noé o nome dele.

Curtir - Responder · 1 - 22 de outubro de 2015 às 19:24

A7 Ele nao perguntou se ele se chama noe, ele mostrou dizendo que queria falar com noe(saber onde esta)

Curtir - Responder · 5 - 22 de outubro de 2015 às 20:03

A8 Ele errou o lugar. Ele [deus] acha que estão construindo errado, era pra ser a arca, até ele [deus] perceber que não está no lugar certo. Era para ele estar na cidade de outra lenda. Curtir - Responder · 12 - 22 de outubro de 2015 às $10: 57$

A9 cara, que tirinha difícil ... se caisse no ENEM eu rodava

Curtir - Responder · $1 \cdot 22$ de outubro de 2015 às 19:25

A10 Achei que ele estivesse fazendo apologia ao Cavalo de Tróia.

Curtir - Responder · 22 de outubro de 2015 às 16:57 - Editado

A11 Sim, é o Cavalo de Tróia. Mas Deus se enganou, queria ir ver o Noé.

Curtir - Responder · 1 - 22 de outubro de 2015 às $16: 57$
A10 Ah sim! Agora entendi. Obrigada! Rs Curtir · Responder · 1 - 22 de outubro de 2015 às 16:59

No primeiro bloco, conforme vimos, o foco da discussão é a compreensão do efeito de humor na tirinha. Percebemos em A1, A3, A5 e A10 que nem todos conseguiram compreender esse efeito, o que leva alguns sujeitos a levantar aspectos do texto a fim de que os demais percebam o propósito constitutivo do humor. Essa cooperação indica o efeito perlocucionário provocado pela tirinha nesses leitores. Ao tentar negociar sentidos para a tirinha, A2, A8 e A11 recorrem aos elementos que emergem da enunciação, incorporando a eles aspectos subjacentes a instâncias discursivas mais remotas, por exemplo, a história da guerra de Tróia, incorporada à explicação de que os gregos construíram esse cavalo de madeira e à confusão na identificação do personagem Noé.

Ainda nesse bloco, outro aspecto que nos chamou a atenção é a discussão entre A6 e A7, voltada para o aspecto gramatical que implicou na queixa de A6, mas que foi logo esclarecida por A7. Notamos que entre os próprios comentários, isto é, na interação entre os sistemas autopoiéticos, existe uma perturbação, o que reforça o argumento de que não existe uma linearidade constitutiva do texto.

Em outro bloco, os sujeitos leitores encaminham a discussão contextualizando-a com conhecimentos advindos da própria mitologia grega, com o intuito de construir comentários engraçados que dialoguem com o texto principal. Conforme vemos no bloco:

B1 Deus se metendo nas áreas de Zeus! kkkkk Curtir · Responder · $11 \cdot 22$ de outubro de 2015 às 16:51

[...]

B2 Zeus deve ter pirado na batatinha!

Curtir - Responder · $5 \cdot 22$ de outubro de 2015 às 11:02

[...]

B3 E Atena aparece de braços cruzados do lado de Deus e fala:

"Algum problema?" (Foi Atena que mandou Ulisses construir o Cavalo de

Troia).

Curtir · Responder · 23 de outubro de 2015 às 11:29

B4 Atuando em jurisdição errada...

Zeus num vai curtir Deus metendo o nariz em área errada....

Hahahahahah

Curtir - Responder .22 de outubro de 2015 às 13:10 
Nesse segundo bloco de comentários, existe um diálogo com o texto principal a fim de desencadear humor. Nesses comentários, percebemos que além de compreender o efeito de humor da tirinha, os leitores valem-se de conhecimentos da própria mitologia grega para estabelecerem um diálogo com o texto principal, por vezes, como B3, dando ideias para o que poderia ter acontecido no desenrolar da narrativa. Compreendemos, em conformidade com os conceitos construídos por Hanks, que, na tentativa de "contextualizar" a tirinha, os leitores recorrem aos processos de emergência e incorporação, buscando reorganizar o discurso a partir do conhecimento das duas histórias retratadas na tirinha.

No terceiro bloco, existe um aparente desvio do tópico da tirinha. Entretanto, o que realmente acontece é que os leitores trazem para a discussão a propaganda do posto Ipiranga, muito conhecida pela circulação via TV. Segundo a propaganda amplamente veiculada, o posto Ipiranga é o lugar onde se encontram as respostas para todas as perguntas dos viajantes. Logo, essa informação é incorporada à discussão que se desenvolve nos comentários da tirinha:

C1 Procura lá no posto Ipiranga que ele deve estar lá

Curtir - Responder $\cdot 1 \cdot 22$ de outubro de 2015 às $11: 26$

C2 "Pergunta no Posto Ipiranga!" kkkkkkkkkkkkkkkkkkkk

Curtir - Responder · 22 de outubro de 2015 às $12: 44$

C3 Pergunta la no posto Ipiranga.

Curtir - Responder $\cdot 2 \cdot 22$ de outubro de 2015 às $12: 36$

C4 Pergunta lá no Posto Ipiranga...!

Curtir - Responder · 1 - 22 de outubro de 2015 às $11: 59$

A partir dessa interação pudemos perceber que, como afirma Marcuschi (2005), o processo de leitura não é linear, pois, por meio de uma relação hipertextual, determinadas expressões ou usos dentro dos textos construídos a partir da tirinha levaram as discussões dos comentários apresentados para outros caminhos que desestabilizam o processo e contribuem para a atualização textual. Esse exemplo ilustra como, em situações reais de interação, o texto se apresenta como um construto linguístico, social e cognitivo, como assevera Beaugrande (1997).

Salientamos que, a todo momento, os sujeitos engajados nesse processo buscaram reorganizar-se dentro desse movimento dinâmico, realizando autopoiese. Tal realidade também corrobora as afirmações de Pellanda (2005), ao reconhecermos no exemplo discutido essa "espiral infinita" construída pela constante (re)significação.

\subsection{Interação 2}

A Interação 2 consta de parte do desenrolar de uma polêmica surgida nas redes sociais que chega a envolver, também, a chamada mídia tradicional impressa. A partir da publicação de um artigo no blog que administra

(http://blogdosakamoto.blogosfera.uol.com.br/),

Leonardo Sakamoto provoca ${ }^{2}$ uma série de leituras "não autorizadas" que levam a alguns efeitos perlocucionários inesperados. No artigo, cujo título é "Três formas para convencer os pobres que aumentar o salário mínimo é ruim", o jornalista critica os que utilizam a mídia como forma de manipular a população contra o aumento do salário mínimo. É o que mostra o parágrafo seguinte:

Toda a vez que chega a época de debates sobre o mínimo, especialistas descabelam-se na mídia com o impacto desse aumento nas contas públicas. Muitas vezes essas análises são produzidas em uma linguagem que poucos conseguem entender, ou seja, em código para atingir aqueles que sabem decodificá-lo, ou seja, um grupo economicamente seleto, ou seja, outras pessoas, mas não você. Há todo um discurso criado e difundido para aceitar tudo como está.

O foco desencadeador da polêmica localiza-se no trecho a seguir, em que o articulista passa a listar e desconstruir as estratégias discursivas que visam à manutenção do status quo. A celeuma se cria em torno do comentário jocoso à proposta de desvincular as

2 Em função do espaço reduzido, mostramos aqui apenas trechos do artigo que consideramos mais relevantes para apoiar a discussão. 
aposentadorias do aumento do salário mínimo. Falando ironicamente da perspectiva dos especialistas, para quem a preocupação do governo deveria ser "a manutenção da mão-de-obra para o capital", o enunciador aproxima a realidade brasileira do universo de "Admirável mundo novo", uma forma de mostrar o ridículo da proposta.

Separei alguns exemplos que já havia trazido aqui ao longo do tempo:

1) "O governo deve desvincular a Previdência do aumento do salário mínimo. Os aposentados não podem receber aumentos na mesma progressão que a população economicamente ativa."

Em outras palavras, quem pode vender sua força de trabalho merece comer, pagar aluguel, comprar remédios. O governo tem que se preocupar em garantir a manutenção da mãode-obra para o capital - o resto que se dane. Para que gastar com quem já não é útil à sociedade com tanta dívida pública para ser paga? Melhor seria instituir de vez que, chegando a tal idade, os idosos pobres deveriam se destinar a instituições parecidas com aquelas do livro "Admirável Mundo Novo", de Aldous Huxley, para serem reciclados. Mais rápido e clean. De repente, pode-se até chamar uma blogueira de moda jabazeira para sugerir decoração para o ambiente de abate dos mais velhos, incentivando - com isso - a liberdade de expressão.

O que se seguiu a essa publicação pode ser resumido por outro texto, do mesmo autor, um quadro em que ele expressa a cronologia da hipertextualidade que se criou em torno de seu discurso anterior. Em seu dizer metafórico, "um grande passeio pela natureza humana na web".

Dez impactos imediatos causados por uma mentira difundida pela rede

Leonardo Sakamoto03/02/2016 13:44 Um jornal impresso de Minas Gerais estampou em sua manchete de capa uma foto minha e uma declaração atribuída a mim - mas que nunca dei - de que "aposentados são inúteis à sociedade". Dentro, uma entrevista - que também nunca concedi - com várias barbaridades contra os aposentados que eu nunca falaria. Ao que tudo indica, alguém pegou um post meu do ano passado, inverteu o sinal de tudo e o transformou em entrevista.

O que acontece no período entre uma difamação ser lançada na rede e o jornal, no caso o "Edição do Brasil", soltar uma nota informando que a entrevista era falsa?

Desta vez, tive a curiosidade de registrar passo a passo o que acontece. Agora trago um grande passeio pela natureza humana na web. Isso pode ser útil quando disserem a vocês algo do tipo: "Ah, relaxa, é só a internet! Não dá em nada."

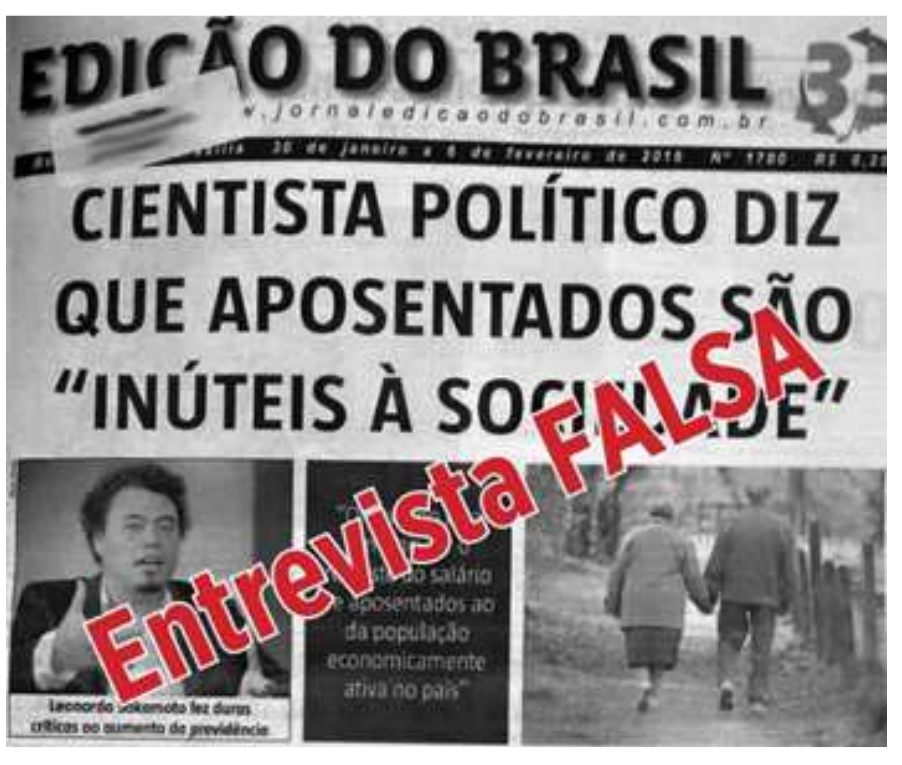

1) Pessoas que não conhecem as ideias deste autor começam a compartilhar o texto, indignadas.

2) Mensagens espumando de raiva chegam até mim. Muitas de aposentados. As mais leves, desejam muita dor e sofrimento.

3) As conhecidas redes de ódio e intolerância, mesmo sabendo que aquilo não condiz com o pensamento deste autor, se apropriam do conteúdo e começam a dispara-lo como se não houvesse amanhã. Surge o primeiro "esse desgraçado é vendido para o governo federal", afirmando que me pagam para falar mal de aposentados.

4) Alguém relaciona a entrevista falsa ao nazismo e diz que o nazismo e o socialismo são a mesma coisa. E que ser de esquerda significa querer acabar com os mais velhos. "Nazista é gente boa perto desse animal", é um exemplo desses elogios. Alguém sugere a hashtag \#Heil_Sakamoto.

\section{5) Chegam as ameaças de morte.}

6) Dou uma explicação simpática no Facebook, dizendo que nunca disse aquilo e aponto para o texto que escrevi defendendo o aumento do salário e que foi desvirtuado por ignorância ou má fé. Há pessoas que não acreditam ("se está se justificando é porque fez") e outras simplesmente ignoram o claro sentido do texto e continuam me xingando.

7) Leitores frequentes do blog, que concordam com ele ou não, tentam convencer os amigos na rede de que aquilo não faz sentido e a acusação é falsa. Mostram o texto original de onde foi inspirada a falsa entrevista, explicam a distorção de tudo. Parte dos amigos dos leitores, em fúria, ignoram as explicações, dizem que nada disso importa. 
8) O primeiro colega jornalista entra em contato para repercutir a matéria. $O$ texto atinge, em pouco tempo, cerca de 15 mil compartilhamentos.

9) O próprio jornal reconhece que não dei a entrevista a eles. Alega que ela foi respondida por uma pessoa que se fez passar por uma assessora minha para prejudicar a mim e ao jornal (justificativa que eles deram em nota que substituiu a entrevista falsa). Claro, nunca me ligaram para checar qualquer informação antes de colocá-la na capa.

10) Mas não importa mais, não depende mais do jornal. As redes de ódio ignoram e continuam divulgando o conteúdo original. Como um desmentido não é lido com a mesma voracidade que uma acusação, e como as pessoas só leem título e foto na internet antes de comentar, a porrada continua. Na verdade, - conteúdo não mais importa, nem o desmentido, nem a informação. Passo a ser obrigado a provar de que não falei aquilo e não o contrário. É raiva, apenas raiva que flui.

Olhando para a rede de intrigas que se criou em torno do artigo do jornalista, podemos dizer que esse é um fenômeno comum no ciberespaço; é o dilúvio eterno de informações em que se perdem os que tentam guiar sua arca em direção à certeza essencial, mas que apenas conseguem construir certezas provisórias, já que "o Todo está definitivamente fora do alcance" (LEVY, 1999, p. 161).

A questão intrigante para nós são as interpretações que se fizeram do parágrafo irônico, o ponto de desequilíbrio gerador dos diferentes tipos de "ajustes operacionais" realizados. Se pensarmos em termos de emergência e incorporação, os mecanismos que, de acordo com Hanks (2008), atuam dinamicamente para ajustar o contexto ao texto, podemos imaginar, por exemplo, que a ironia, o recurso usado pelo enunciador para ridicularizar o discurso dos especialistas alvo de sua crítica, não foi percebida em função do possível desconhecimento do conteúdo da obra "Admirável mundo novo" por parte dos leitores.

Seguindo outra orientação, com base numa hipótese distinta, poderíamos pensar que a explicação seria dada pelo próprio tipo de experiência com a leitura na web. Como denuncia o próprio autor, "as pessoas só leem título e foto na internet antes de comentar". O tipo de perturbação sofrida pelo leitor na
Web seria diferente do que ele teria em outro ambiente. Aqui podemos lembrar o que afirma Franco (2011): "Por considerarmos o homem, neste caso o leitor, um sistema complexo, sabemos que ele carrega suas próprias experiências e conhecimento de mundo, e, portanto, não podemos prever com exatidão como será sua interação com o texto." Diríamos que o próprio papel social (em termos de GOFFMAN, 2011) desempenhado na web, o leitor enquanto comentarista de blog, interferiria no tipo de relação com o texto.

E, falando em papel social, refletimos ainda sobre outro tipo de leitor, que a nosso ver teria apresentado outra forma de reagir à perturbação provocada pelo texto irônico; seria o profissional de mídia, que, segundo denuncia o articulista Sakamoto, publicou em um jornal impresso uma foto sua (do Sakamoto) e uma falsa declaração que lhe foi atribuída, conforme é mostrado na imagem. O tipo e a sequência de coordenações de coordenações de ação que se teria desenvolvido no episódio em questão fica de certo modo opaco para nós, que tentamos interpretar o processo a partir dos trechos a que tivemos acesso. Podemos entender, porém, que o papel social, aliado a outras inúmeras experiências vividas pelos atores (em termos goffmanianos) deve ter interferido de modo decisivo para que o trecho irônico tenha sido descontextualizado e recontextualizado de modo a "dizer" o contrário do que pretendia o autor.

$E$ os leitores do jornal que não aceitaram a explicação e continuaram sem rever suas interpretações? Considerando-se a perspectiva da complexidade, são múltiplos os fatores que interagem e apontam para múltiplas probabilidades de acoplamento.

Tentando agora olhar de modo mais geral para este bloco de interações que envolve os trechos aqui expostos, um trecho rizomático (LÉVY, 1999), podemos dar conta de uma perturbação primeira, o parágrafo irônico, que gera coordenações de coordenações de ações resultando em leituras "desautorizadas", as quais, por sua vez, geram perturbação no autor-leitor, o jornalista Leonardo Sakamoto. Este, finalmente, demonstra sua tentativa de responder à perturbação, ao escrever o segundo texto aqui discutido: "Dez impactos 
imediatos causados por uma mentira difundida pela rede". Para nós, a elaboração dessa lista recheada de ironias, uma marca de seu estilo, pode ser entendida como uma tentativa de reorganizar o sistema, de produzir um fechamento.

\section{Considerações finais}

Neste artigo tivemos como propósito discutir a leitura a partir de alguns trabalhos que já promovem reflexões sobre essa temática e com base em teorias que apontam para a complexidade nos estudos da linguagem. Considerando que nosso foco de estudo é o texto visto como um evento comunicativo que se configura e reconfigura cada vez que se atualiza via processo de leitura, entendemos que não há como separar esses dois temas. Assim, a discussão que desenvolvemos aqui mesclou ideias advindas de campos teóricos distintos, mas que, a nosso ver, têm em comum uma visão não previsível, não estática e não linear dos fenômenos da linguagem. Aproveitando os insights de Pellanda (2007) e Franco (2011), admitimos a leitura como um fenômeno complexo e selecionamos, para tentar demonstrar isso, duas interações via web.

Conforme explicitamos, nosso intento, ao selecionar para a análise textos que retratam interações na Internet, foi tentar demonstrar como a compreensão leitora, que ficaria de certo modo à mostra nos comentários, pode ser considerada um processo recorrente de coordenações de coordenações de ações. Devemos aqui admitir que a ideia de explicar o processo de leitura pelo viés da complexidade já fora aventada por Pellanda (2007). De nossa parte, entendemos que um diálogo poderia ser estabelecido entre as noções de autopoiese, de Maturana e Varela, e as de emergência e incorporação, propostas por Hanks.

Analisando dois tipos de interação desencadeados por gêneros muito distintos -uma tirinha humorística e um artigo de opinião -, pudemos perceber que em ambos os casos a leitura pode ser vista como um movimento recursivo de tentativa de reorganização dos sistemas cognitivos em resposta às contínuas perturbações sofridas pelos interactantes. Entendemos que, durante essa recursão contínua, os mecanismos de emergência e incorporação funcionaram para produzir constantes ajustes na compreensão, embora nem sempre produzindo os sentidos esperados ou "desejados".

Como conclusão de ordem prática, chamamos a atenção para a necessidade de se reverem as noções de texto e de leitura em sala de aula. A pergunta que fica é: Se ler é interagir com outros sistemas, é dar respostas às perturbações que sofremos e provocamos, será possível promover o desenvolvimento da compreensão leitora por meio de sequências didáticas rígidas, que exigem respostas predeterminadas?

\section{Referências}

BAUMAN, R. A World of Others' Words: Cross-Cultural Perspectives on Intertextuality. Oxford: Blackwell Publishing, 2004.

BEAUGRANDE, Robert de. New foundations for a science of text and discourse. Freedom of access to knowledge and society through Discourse. Norwood: Ablex, 1997.

BENTES, A. C.; REZENDE, R. C. Texto: conceitos, questões e fronteiras [com]textuais. In: SIGNORINI, I. (org.). [Re]discutir texto, gênero e discurso. São Paulo: Parábola, 2008. p. 19-46.

FRANCO, C. de P. Por uma abordagem complexa de leitura. In: TAVARES, K.; BECHER, S.; FRANCO, C. (Orgs.). Ensino de Leitura: fundamentos, práticas e reflexões para professores da era digital. Rio de Janeiro: Faculdade de Letras da UFRJ, 2011. p. 26-48. Disponível em: <http://www.claudiofranco.com.br/textos/franco eb ook leitura.pdf> Acesso em: 29 ago. 2015.

GOFFMAN, E. Ritual de interação: ensaios sobre o comportamento face a face. Tradução de Fábio Rodrigues Ribeiro da Silva. Rio de Janeiro: Vozes, 2011.

HANKS, W. F. O que é contexto? In: Língua como prática social: das relações entre língua, cultura e sociedade a partir de Bourdieu e Bakhtin. São Paulo: Cortez, 2008. p.169-203.

LÉVY, P. Cibercultura. São Paulo: Editora 34, 1999.

MARCUSCHI, L. A. A coerência no hipertexto. In: COSCARELLI, C. V.; RIBEIRO, A. E. (Org.). Letramento Digital: Aspectos sociais e possibilidades pedagógicas. 1ed. Belo Horizonte: Autêntica, 2005. p. 185-208. 
MATURANA, H.; VARELA, F. A Árvore do conhecimento: as bases biológicas do entendimento humano. Campinas: Psy II, 1995.

MATURANA, H. Cognição, ciência e vida cotidiana. Tradução de Cristina Magro e Victor Paredes. Belo Horizonte: UFMG, 2001.

PELLANDA. N. M. C. Leitura e complexificação. In: CONGRESSO DE LEITURA DO BRASIL, 16.,
2007, Campinas. Anais... Campinas: UNICAMP, 2007. Disponível em:

$<$ http://alb.com.br/arquivomorto/edicoes anteriores/anais 16/sem05pdf/sm05 ss14_06.pdf>. Acesso em: 29 jan. 2016.

Leitura como processo cognitivo complexo. In: OLMI, A.; PERKOSKI, N. (Org.). Leitura e cognição: uma abordagem transdisciplinar. Santa Cruz do Sul: EDUNISC, 2005. p. 51-69

\section{COMO CITAR ESSE ARTIGO}

BARROS DEMÉTRIO, Alana Kercia; PEREIRA ALVES, Luiz Eleildo; ARAÚJO COSTA, Maria Helenice. Compreensão (con)textual em mídias sociais digitais. Signo, Santa Cruz do Sul, v. 41, n. 72, out. 2016. ISSN 1982-2014. Disponível em: <https://online.unisc.br/seer/index.php/signo/article/view/7247>. Acesso em: . doi: http: //dx.doi.org/10.17058/signo.v41i72.7247. 